\title{
Correspondence
}

\section{Saline through the epidural needle: what volume?}

To the Editor:

I read with interest the article by Gadalla et al. ${ }^{1}$ However, it seems to me that the same effect can be accomplished with a smaller volume of saline administered through the epidural needle. In the author's practice the loss of resistance to saline (LORS; $1.5-2$ $\mathrm{mL}$ ) is used for the identification of the epidural space with an 18-gauge Tuohy-Schliff epidural needle. A 27 -gauge Pencan needle is inserted inside the epidural needle, $5 \mu \mathrm{g}$ of fentanyl combined with $2.5 \mathrm{mg}$ of levobupivacaine is injected intrathecally, the spinal needle is withdrawn, and 2 to $2.5 \mathrm{~mL}$ of normal saline is injected through the epidural needle. A 20-gauge multi-orifice epidural catheter is then inserted into the epidural space. Using this technique I have had an incidence of intravascular cannulation by the epidural catheter of $4 \%$ (unpublished data). This may be explained by the fact that with the LORS technique as opposed to the loss of resistance to air technique (LORA) some fluid is injected in the epidural space at the time of the epidural space identification. However, and importantly to the contrary, Rolbin et al. noted that there was no advantage to the injection of $3 \mathrm{~mL}$ of fluid into the epidural space before insertion of an epidural catheter. ${ }^{2}$ In conclusion I would challenge the authors to study several groups of patients receiving different volumes of normal saline (for example $2.5,5,10 \mathrm{~mL}$ ) and use both LORS and LORA techniques for identification of the epidural space.

Krzysztof M. Kuczkowski

San Diego, California

\section{References}

1 Gadalla F, Lee SH, Choi KC, Fong J, Gomillion MC, Leighton $B L$. Injecting saline through the epidural needle decreases the iv epidural catheter placement rate during combined spinal-epidural labour analgesia. Can J Anesth 2003; 50: 382-5.

2 Rolbin SH, Halpern SH, Braude BM, Kapala D, Unger $R$, Radhakrisna $S$. Fluid through the epidural needle does not reduce complications of epidural catheter insertion. Can J Anaesth 1990; 37: 337-40.

\section{REPLY:}

I am gratified with Dr. Kuczkowshi's interest in our study ${ }^{l}$ and am in complete agreement that there is room for more work in this area. In fact, we are already in the process of designing a follow-up clinical study using different volumes of normal saline.

Prior to this we had not considered comparing loss of resistance to saline and loss of resistance to air techniques, but may act on his suggestion.

Farida Gadalla MD

New York, New York

\section{Reference}

1 Gadalla F, Lee SH, Choi KC, Fong J, Gomillion MC, Leighton $B L$. Injecting saline through the epidural needle decreases the iv epidural catheter placement rate during combined spinal-epidural labour analgesia. Can J Anesth 2003; 50: 382-5.

\section{Avoiding the accidental iv injection of local anesthetics}

\section{To the Editor:}

A recent article by Favier et al., highlighted the successful resuscitation of a patient who experienced severe bupivacaine cardiotoxicity. ${ }^{1}$ Such incidents are not uncommon in anesthesia practice. ${ }^{2}$ The authors have concomitantly suggested a number of preliminary measures to prevent such mishaps. They recommend the absolute necessity of careful labelling of syringes and the use of specific syringes with large volumes for local anesthetics. However, both measures have inherent drawbacks. Errors with labelling of syringes have been featured by various authors. Labelling marcaine for bupivacaine has been mistaken for morphine and the bupivacaine label may be mistaken for butorphanol or buprenorphine. ${ }^{3}$ On the other hand, the use of large volume syringes (20-30 $\mathrm{mL}$ ) may lead to the accidental administration of relatively large volumes of local anesthetics for neuraxial block with catastrophic results. ${ }^{4}$

Loss of resistance is the commonest method used to identify the epidural space. This is best accomplished using a $10-\mathrm{mL}$ prepackaged plastic or glass syringe. ${ }^{5}$ The distinct colour of the plunger of the 


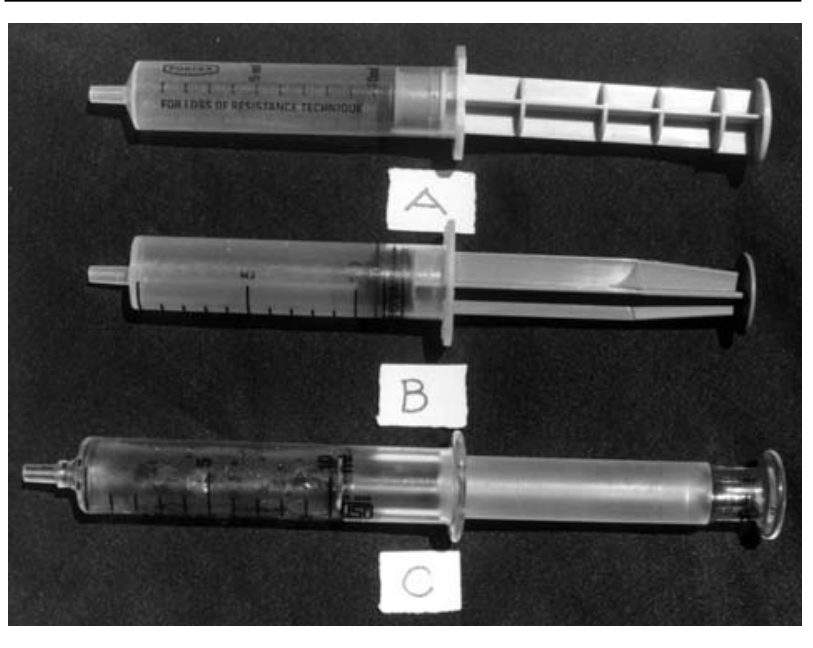

FIGURE Showing the plungers of various syringes. A) Loss of resistance syringe (Portex); B) disposable plastic syringe; C) glass syringe.

prepackaged syringe, for instance blue in the Portex epidural set with both horizontal and vertical flanges (in contrast to vertical flanges only or a smooth plunger) can avoid confusion between syringes (Figure). The feel and weight of the loss of resistance syringe with free and consistent movement of the plunger are well discernable to the experienced hand. One may preferably use such dedicated syringes for neuraxial drug administration. Further, once the syringe is filled with the local anesthetic solution, it should preferably be attached to the Luer lock connector on the epidural catheter rather than kept along with the other syringes containing drugs intended for parenteral administration. Alternatively, syringes containing local anesthetics may be kept along with the Luer lock adaptor in a sterile drape, beside the patient.

Such simple measures may hopefully, help avoid accidental $i v$ injections of local anesthetics.

Rajesh Mahajan MD

Jammu, India

\section{References}

1 Favier JC, Da Conceiçao M, Fassassi M, Allanic L, Steiner T, Pitti R. Successful resuscitation of serious bupivacaine intoxication in a patient with pre-existing heart failure. Can J Anesth 2003; 50: 62-6.

2 Karaca S, Unlusoy EO. Accidental injection of intravenous bupivacaine (Letter). Eur J Anaesthesiol 2002; 19: 616-7.

3 Radhakrishna $S$. Syringe labels in anaesthetic induction rooms. Anaesthesia 1999; 54: 963-8.
4 Thomas TA, Cooper GM. Maternal deaths from anesthesia. An extract from why mothers die 1997-1999. The confidential enquiries into maternal death in the United Kingdom. Br J Anaesth 2002; 89: 499-508.

5 Armitage EN. Lumbar and thoracic epidural block. In: Wildsmith JAW, Armitage EN, McClure JH (Eds.).

Principles and Practice of Regional Anaesthesia, 3rd ed. New York: Churchill Livingstone; 2003: 139-68.

\section{REPLY:}

I agree with Dr. Mahajan that careful labelling of syringes is not sufficient. The use of pre-printed labels with colour codes is an important measure to limit drug confusion. For example, a grey colour code could be used for local anesthetics (Time Med labelling systems $®$, Burr Ridge, IL, USA). A colour code is a visual alarm to avoid syringe swaps.

I also concur with the recommendation to use 10-mL distinct syringes for neuraxial drug administration. However, the use of these 10-mL specific syringes is uncomfortable for peripheral blocks when 20 to $40 \mathrm{~mL}$ volumes are injected. I propose the use of 30-mL Luer-lock syringes for such blocks: 20 to $30 \mathrm{~mL}$ injection volumes are common and 30-mL Luer lock syringes are not frequently used for other purposes (in France). Careful incremental injections with repeated aspiration tests are primordial. In our case report, ${ }^{1}$ 20-mL syringes where prepared for postoperative analgesia. The contents of one syringe were injected iv accidentally. If a colour code or a 30-mL syringe had been used, we may, hopefully, not have had to treat the dramatic consequences of this in injection of $20 \mathrm{~mL}$ of $0.375 \%$ bupivacaine $+15 \mu g$ clonidine.

Jean-Christophe Favier MD

Laurent Allanic MD

Metz Armées, France

\section{Reference}

1 Favier JC, Da Conceiçao M, Fassassi M, Allanic L, Steiner T, Pitti R. Successful resuscitation of serious bupivacaine intoxication in a patient with pre-existing heart failure. Can J Anesth 2003; 50: 62-6.

\section{Choosing a laryngoscope blade: straight vs curved}

To the Editor:

Whilst we are impressed that Arino et al. ${ }^{1}$ recruited and randomized 500 subjects for a study comparing direct laryngoscopy using five different laryngoscopes by a single operator, we question their conclusion that 